\title{
Behavior of Reinforced Concrete Beams using Wire Rope as Internal Shear Reinforcement
}

\author{
Gerald M. Colyvas \\ Civil Engineering Department \\ Pan African University, Institute for \\ Basic Sciences, Technology and \\ Innovation \\ Nairobi, Kenya \\ gerald.colyvas@gmail.com
}

\author{
Yann Malecot \\ Institute of Engineering \\ University of Grenoble Alpes \\ CNRS \\ Grenoble INP \\ Grenoble, France \\ yann.malecot@3sr-grenoble.fr
}

\author{
Yannick Sieffert \\ Institute of Engineering \\ University of Grenoble Alpes \\ CNRS \\ Grenoble INP \\ Grenoble, France \\ yannick.sieffert@3sr-grenoble.fr
}

\author{
Sylvester Aboudha \\ Civil Engineering Department \\ Univesity of Nairobi \\ Nairobi, Kenya \\ sochieng@yahoo.com
}

\author{
Christopher Kanali \\ Agricultural and Biosystems Engineering Department \\ Jomo Kenyatta University of Agriculture and Technology \\ Nairobi, Kenya \\ ckanali@jkuat.ac.ke
}

\begin{abstract}
Wire ropes as internal shear reinforcementscould are an economic alternative to conventional stirrups in rectangular concrete beams, mainly due to their attractive advantages such as high flexibility, light weight, and strength. The aim of this study is to enhance the understanding of the shear behavior of concrete beams with continuous spiral-type wire rope as internal shear reinforcement. In order to achieve this objective, an experimental program involving the testing of six beam specimens under fourpoint load was conducted. Digital image correlation technique was employed to study the crack formation and propagation in the beam specimens. The test results demonstrated that using continuous spiral-typewire rope as shear reinforcement is highly favorable for diagonal crack control. In particular, spiral-type wire rope specimens attained serviceability crack width at a higher load than that of normal stirrup beam specimens.
\end{abstract}

Keywords-digital image correlation; shear reinforcements; wire rope reinforcements

\section{INTRODUCTION}

The design and complexities of reinforced concrete structures have evolved to the point that concrete structures are designed with ever increasing reinforcements and concrete design requirements [1]. This is especially evident in areas of seismic design considerations and in most sensitive and massive structures [2] such as nuclear reactors and military facilities. In such cases the use of conventional shear stirrups, especially in concrete beams, increases the cost of the project due to the nature of their installation. This problem is usually amplified when high strength steel is used instead of normal steel. Studies have been carried out to find alternative methods for shear reinforcement in concrete members [3-6]. Most of the proposed methods, such as the use of steel and carbon fiber reinforcements and steel plates are quite costly in terms of their placement and require special labor skills. The use of continuous spiral shear reinforcement as highlighted in [7] reduces labor costs with respect to the installation of once closed stirrups. It is also possible to automate the process of continuous spiral shear reinforcement placement which could tremendously reduce the project duration. Several studies have been devoted to studying the response of concrete members reinforced with continuous spiral shear configuration [1,7-10]. Continuous spiral reinforcement has been reported to be more effective in confining the concrete $[1,7]$ than individual stirrups, thus aiding in enhancing the concrete compressive strength which increases shear load at the development of the first inclined shear cracking. A major challenge encountered in continuous spiral reinforcement, especially in rectangular concrete beams, is the bending of the steel bars. This challenge is amplified when using high strength steel bars [7].

Wire ropes on the other hand, offer tremendous advantages in terms of being lightweight and having high strength and flexibility [1]. A continuous spiral configuration could be easily achieved and in particular, the difficulties encountered in bending higher strength steel bars could be overcome. It was also reported that the increasing rate of diagonal crack width against the applied loads was smaller in beams with spiral type wire ropes compared to the beams with closed stirrups. Most of the experimental investigations to study the shear response of continuous spiral reinforced concrete beams were performed using normal steel [7, 9-11] and majorly on the rectangular concrete sections [12]. To the best of our knowledge, only authors in [1] reported on the application of high strength wire ropes to T-section concrete beams, therefore, there is still insufficient knowledge on the response on rectangular concrete beams with continuous spiral-type wire rope spiral reinforcement. In order to gain more insight on the actual response of wire rope shear reinforced rectangular concrete 
beams, in this study, Digital Image Correlation (DIC) method, which is an effective tool for studying fracture behavior of materials [13-19] was employed in order to study the shear response of wire rope spiral reinforced concrete rectangular beams. Crack patterns, crack width and their propagation were compared with those of the control beams with conventional stirrups.

\section{EXPERIMENTAL PROCEDURE}

\section{A. Design of Test Specimens}

The experimental procedure for this study consisted of six reinforced concrete beams with $2200 \mathrm{~mm} \times 400 \mathrm{~mm} \times 300 \mathrm{~mm}$ dimensions (length $\times$ width $\times$ depth). These were subjected to either monotonic or direct cyclic four point bending loading as shown in Figure 1. Three beams had normal shear stirrups and were used as control while the other three beams were shear reinforced with continuous spiral-type wire ropes as shown in Figures 2 and 3 respectively. In this study, prefixes 'NSB' and 'WRB' will be used to identify the beam specimens, as Normal Stirrups Beam and Wire Rope Beam, respectively. Details of the beam specimens such as compressive concrete strength $f c d$ $(\mathrm{MPa})$, percentage of longitudinal $\rho l(\%)$, and shear $\rho t(\%)$ reinforcements, loading at first crack $P c r$ and ultimate load Pmax, cracking inclination angle $\theta\left({ }^{\circ}\right)$ and loading type are given in Table I. The test results from standard tensile tests for both steel and wire rope reinforcements are given in Table II.

\section{B. Experimental Imaging Set-up}

\section{1) Camera and lighting}

Two NIKON® D800E high resolution cameras were used to track motion. Maximum resolution of $7360 \times 4912$ with 12 bit tone was used in order to obtain the most accurate DIC analysis results. At this resolution, 10.22 pixels represent $1 \mathrm{~mm}$ on the beam specimen. The time interval between images was set to be $3 \mathrm{~s}$ for monotonic and $5 \mathrm{~s}$ for cyclic tests respectively. Measurement precision with a high-resolution camera depends in large part on image brightness, hence background lighting is required [16]. In this study, two equal lighting sources positioned $2 \mathrm{~m}$ from the specimen were used. Two covers were added behind each section of the beams to protect images from light interference.

\section{2) Speckle Patterns}

In order to obtain precise measurements, the DIC technique requires speckle patterns to distinctly exhibit different gray scale distribution characteristics [15]. This step could not be completed solely with the natural specimen surface. A random painted speckle pattern then had to be added. Speckle patterns were applied using spray paint and special technique of controlling amount of paint from the nozzle by slightly covering the nozzle with a thumb. This technique ensured both a random dot size (between 0.3 and $0.6 \mathrm{~mm}$ ) and a satisfactory dot density, which were obtained within a relatively short time. To achieve this, white paint was first applied to the area of study and black speckles were then added to ensure proper visibility.

\section{3) Ncorr}

The DIC analysis in this study was done using the open source 2D digital image program Ncorr. Ncorr uses 2D DIC algorithms developed and presented in [20], and is contained within the MATLAB ${ }^{\circledR}$ environment. The images collected during the experiments were then processed using Ncorr to calculate the displacement and strain fields. For computing displacements using DIC, a subset was chosen from the reference image and its corresponding location tracked in the deformed image. The square subset size of $20 \times 20$ pixels was selected after performing a sensitivity analysis. For strain calculation, Ncorr uses a least squares plane fit to a contiguous circular group of displacement values. After carrying sensitivity analysis, the radius was set to 5 pixels prior to strain computation.

\section{Test Procedures and Instrumentation}

A typical four-point bending scheme and setup as shown in Figure 1 was selected. Beams were simply edge-supported on roller supports $2000 \mathrm{~mm}$ apart using rigid laboratory supports. A span of $500 \mathrm{~mm}$ from both ends was required to have shear failure that was used to study shear crack initiation and propagation using DIC. Due to the large size of the loading frame columns, it was not possible to obtain a good visualization of the shear part of the beam hence a steel spreader beam was placed on top of the beam. The imposed loading was henceforth applied at two points $1000 \mathrm{~mm}$ apart on the steel spreader beam. In this way, the lengths of the shear span of the specimens were maintained at $500 \mathrm{~mm}$. The displacement was imposed with at rate of $0.02 \mathrm{~mm} / \mathrm{sec}$ using two $200 \mathrm{kN}$ capacity pinned-end actuators whose loading forces were measured by load cells with accuracy of $0.05 \mathrm{kN}$. For direct cyclic loading, the load was applied with a displacement set to previously defined forces as shown on Figure 4. Five Linear Variable Differential Transformers (LVDT) were employed to measure the beam deflection at three distinct locations using two LVDTs on the supports as references (see Figure 1). Measurements for load and deflection were taken and recorded continuously during the tests until the ultimate bearing capacity of the beams was attained.

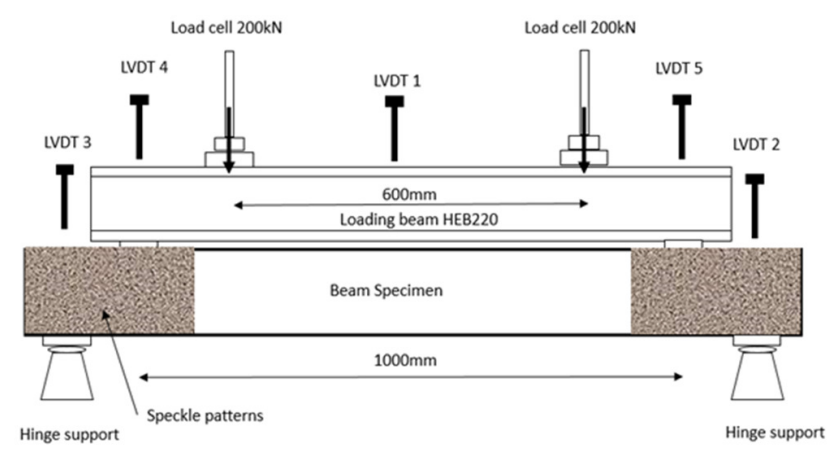

Fig. 1. Details of the experimental setup.

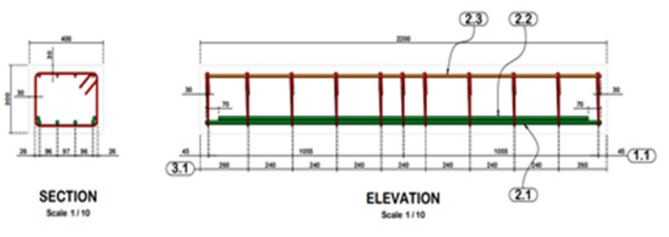

Fig. 2. Reinforcement details of an NSB specimen. 
TABLE I. DETAILS OF THE BEAM SPECIMENS

\begin{tabular}{|l|c|c|c|c|c|c|c|}
\hline Specimen & $\begin{array}{c}\boldsymbol{f c d} \\
(\mathbf{M p a})\end{array}$ & $\begin{array}{c}\boldsymbol{p l} \\
(\mathbf{\%})\end{array}$ & $\begin{array}{c}\boldsymbol{p t} \\
(\mathbf{\%})\end{array}$ & $\begin{array}{c}\boldsymbol{P m a x} \\
(\mathbf{k N})\end{array}$ & $\begin{array}{c}\boldsymbol{P} \boldsymbol{c r} \\
(\mathbf{k N})\end{array}$ & $\begin{array}{c}\boldsymbol{\theta} \\
\left({ }^{\circ}\right)\end{array}$ & $\begin{array}{c}\text { Loading } \\
\text { type }\end{array}$ \\
\hline NSB-001 & 21.4 & 1.12 & 0.104 & 157.2 & - & 33.6 & Direct cyclic \\
\hline NSB-002 & 20 & 1.12 & 0.104 & 159.3 & 110 & 55 & Direct cyclic \\
\hline NSB-003 & 19.6 & 1.12 & 0.104 & 159.5 & 85 & 42 & Monotonic \\
\hline WRB-001 & 21.4 & 1.12 & - & 158.7 & - & 35.5 & Direct cyclic \\
\hline WRB-002 & 20 & 1.12 & - & 157.8 & 130 & 26 & Direct cyclic \\
\hline WRB-003 & 19.6 & 1.12 & - & 158.4 & 138 & 33 & Monotonic \\
\hline
\end{tabular}

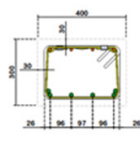
SECTION

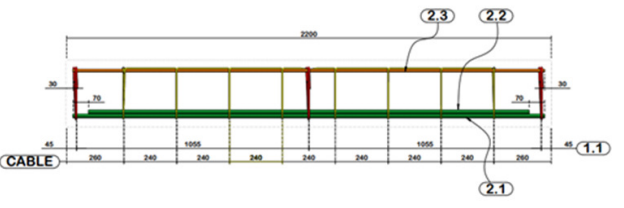

ELEVATION

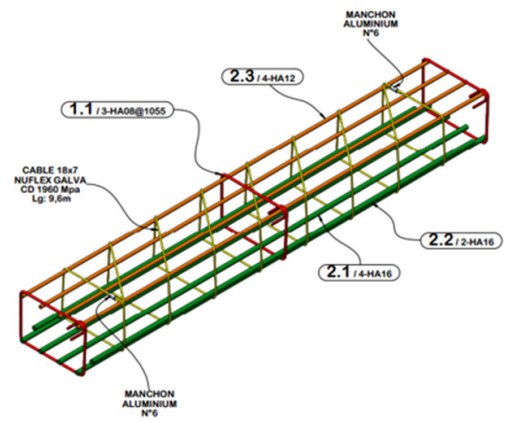

Fig. 3. Reinforcement details of a WRB specimen.

TABLE II. MECHANICAL PROPERTIES OF STEEL AND WIRE ROPE REINFORCED BARS

\begin{tabular}{|c|c|c|c|c|}
\hline Type & $\begin{array}{c}\text { Diameter } \\
(\mathbf{m m})\end{array}$ & $\begin{array}{c}\boldsymbol{F y} \\
(\mathbf{M P a})\end{array}$ & $\begin{array}{c}\boldsymbol{F u} \\
(\mathbf{M P a})\end{array}$ & $\begin{array}{c}\boldsymbol{E s} \\
(\mathbf{G P a})\end{array}$ \\
\hline Mild steel bar & 8 & 420 & 600 & 225 \\
\hline Wire rope & 6 & 450 & 850 & 90 \\
\hline
\end{tabular}

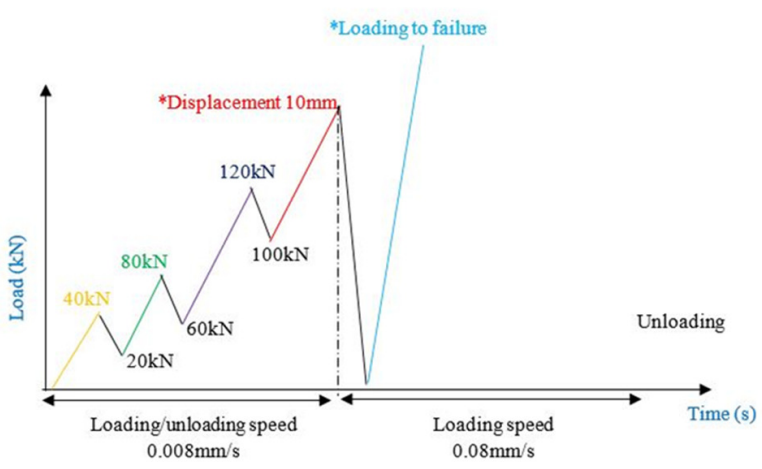

Fig. 4. Loading layout for the direct cyclic test.

\section{RESULTS AND DISCUSSION}

\section{A. Load Deflection Curves}

A summary of the beam shear test results is presented in Table I. The values represent the measured cracking and ultimate load, and the crack inclination angles $\theta$ at failure. The applied load-mid-span deflection curve for beam specimens under monotonic loading is shown in Figure 5 whereas Figures 6 and 7 show the load-mid-span deflection curves for beams under cyclic loading. All the beams from both groups exhibited similar behavior both in monotonic and direct cyclic loading. From Table I, it can be seen that all the beam specimens had approximately the same ultimate load regardless of smaller cross-sectional area of wire ropes compared to steel rebars. In Figures 5 and 6, a marginal improvement of initial stiffness in the beams with wire rope reinforcement before the cracking load was observed. However, for the case of monotonic loading, immediately after the formation of the first diagonal crack (see Figure 5) there was a decrease in the stiffness of the specimen WRB-3.

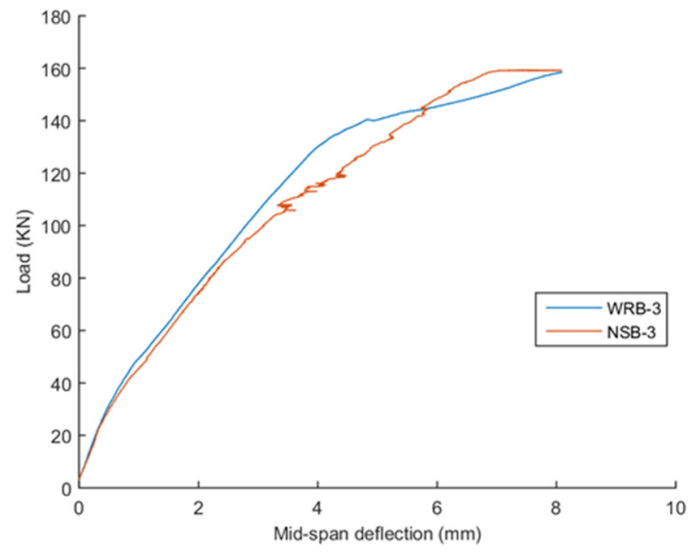

Fig. 5. Load deflection curve-monotonic loading.

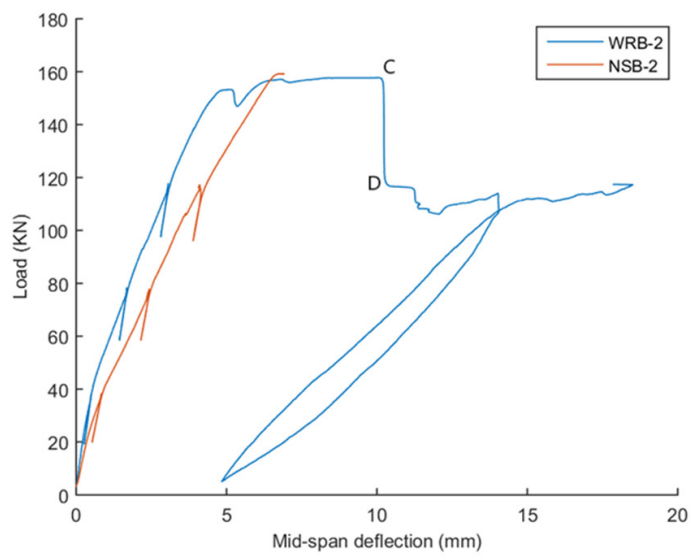

Fig. 6. Load deflection curve-direct cyclic loading.

As shown in Figure 6, there was a sudden decrease in ultimate load at point $\mathrm{C}$ to point $\mathrm{D}$. This was accompanied by an increase of the number of cracks (formation of new cracks). A probable explanation for this is the loss of bond between concrete and wire rope. The measured inclination of the cracking angle of all tested beam specimens in this study, are shown in Figures 8 and 9 and presented in Table I. These results indicate that the wire rope shear reinforced beams exhibited a slightly lower inclination of the cracking angle compared to the corresponding beams with normal stirrups. 


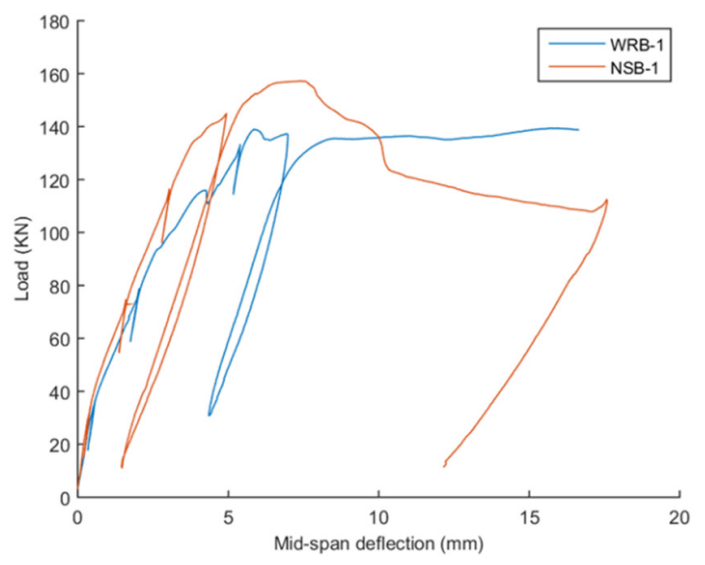

Fig. 7. Load deflection curve-direct cyclic loading.

(a)

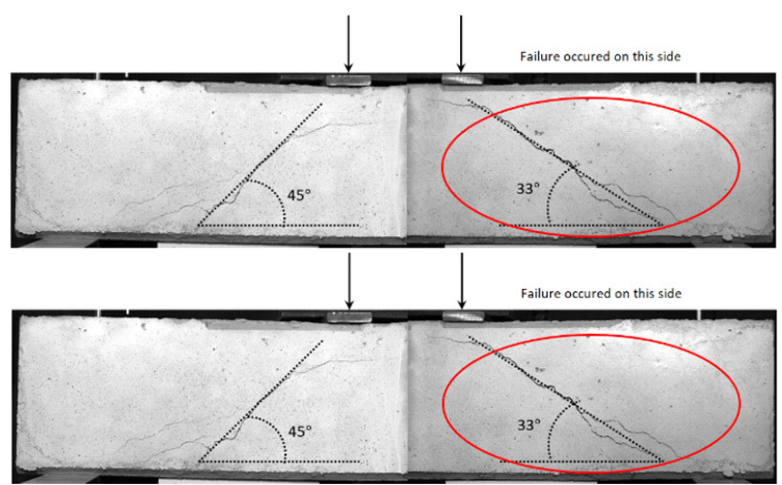

Fig. 8. Beams at failure under monotonic loading (the central part of the beam is not shown): (a) WRB-3, (b) NSB-3.

(a)

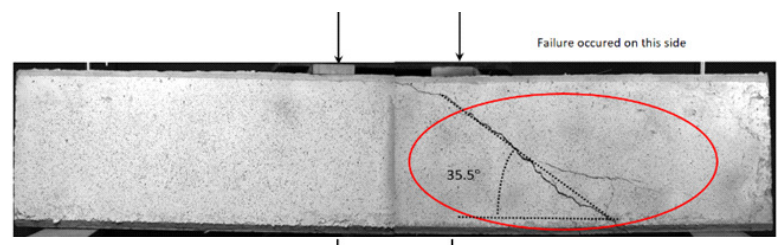

(b)

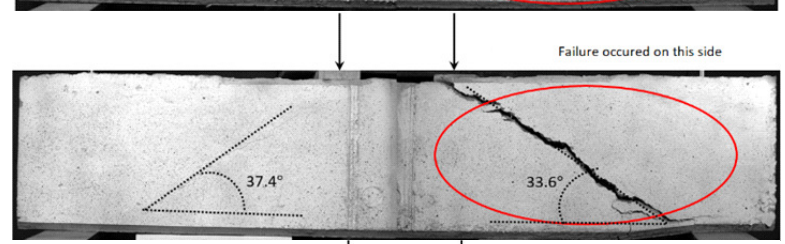

(c)

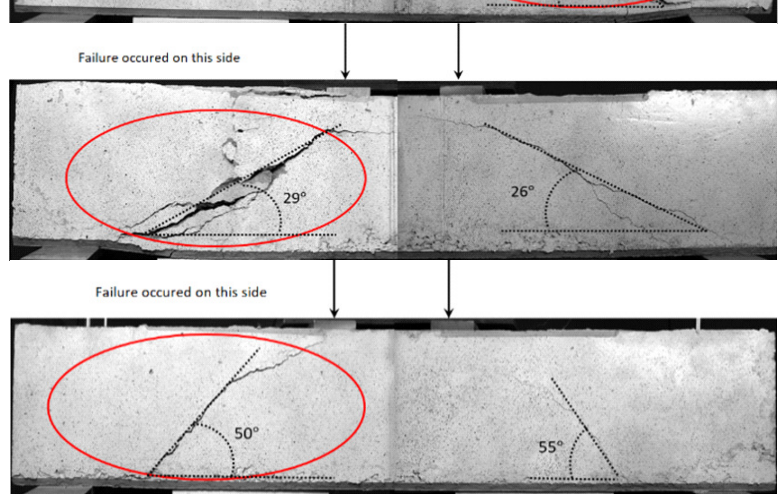

Fig. 9. Beams at failure under direct cyclic loading (the central part of the beam is not shown): (a) WRB-1, (b) NSB-1, (c) WRB-2, and (d) NSB-2.
This could be due to the confinement effect as reported by [7] who observed that continuous spiral-type configuration confines more concrete than conventional stirrups. A more confined concrete resists to shear stresses better. These obesrvations also indicate that all the beam specimens failed in shear mode by forming a diagonal tension shear crack.

\section{B. Digital Image Correlation Results}

Displacement fields obtained from Ncorr were further processed with MATLAB in order to obtain the deflection at different points of the beams. In order to validate the obtained results from the DIC technique, the displacements at the beam support obtained from DIC were compared with the ones recorded by LVDT as shown in Figure 10. We can see a perfect match between the displacements measured by LVDT and the ones measured by DIC. The difference is always less than $3 \%$. DIC method is therefore a suitable displacement measurement method as also reported in [15-18].

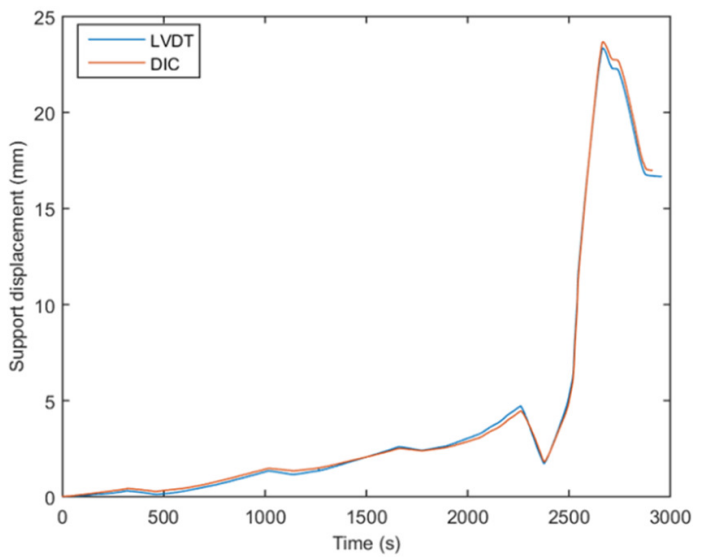

Fig. 10. Comparison between the beam support displacements obtained from DIC analysis and LVDT measurements.

\section{1) Crack Patterns}

Crack patterns and their development could be tracked in a very detailed manner with the DIC method. In this study, this method was used to investigate the cracking process (crack initiation and propagation) and to measure crack width during the test. Figures 11 and 14 show the developed crack patterns and the corresponding loads in $\mathrm{kN}$ for the beam specimens NSB-2, WRB-2, NSB-3 and WRB-3. Crack patterns are longitudinal strain fields, $\varepsilon x$, obtained from Ncorr program. In the specimens NSB-1 and WRB-1, the cracks appeared on the back side of the beam therefore it was not possible to capture their development during the early stages of the test. It was observed that cracks formed earlier on one side of the beam compared to the other, hence the results displayed in this section are only for the side on which cracks formed earlier during loading history. The crack patterns obtained with the DIC method were first compared with the observed crack patterns shown in Figures 8 and 9. From these figures, it can be clearly seen that the horizontal displacement profile of the DIC qualitatively agreed with the crack pattern observed on the specimen. A combination of flexural cracks with shear tension cracks was observed consistently in all the beams as flexural 
cracks were observed during the first loading (Figures 11(a) and (b)). The flexural cracks extended to shear tension cracks as the load increased (Figures 11(d) and 11(g)). No premature failure due to anchorage of the tension reinforcement or due to over compression of the supports was observed during the loading history. From these figures, it can also be seen that cracks have similar shapes in both beam categories.

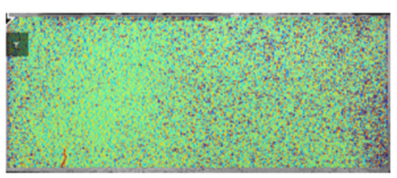

(a) WRB-3 at $36 \mathrm{KN}$

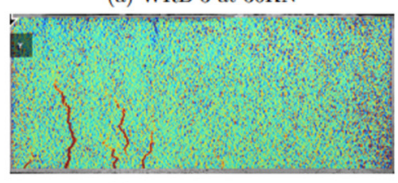

(c) WRB-3 at $94 \mathrm{KN}$

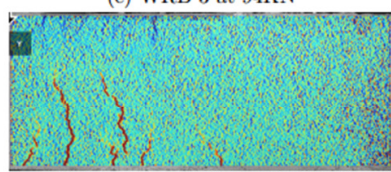

(e) WRB-3 at $120 \mathrm{KN}$

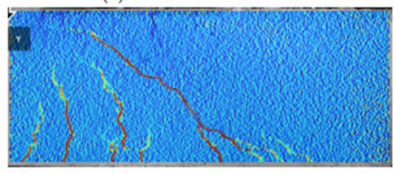

(g) WRB-3 at $140 \mathrm{KN}$

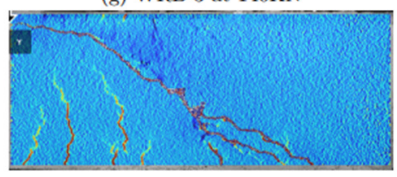

(i) WRB-3 at $150 \mathrm{KN}$

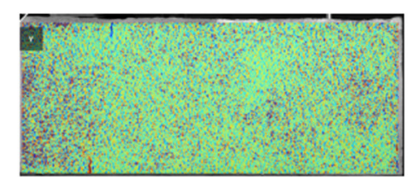

(b) NSB-3 at $32 \mathrm{KN}$

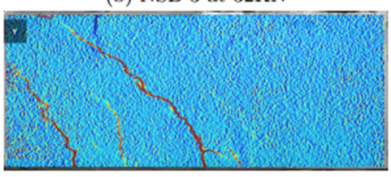

(d) NSB-3 at $94 \mathrm{KN}$

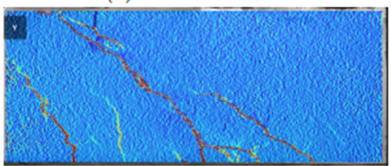

(f) NSB-3 at $120 \mathrm{KN}$

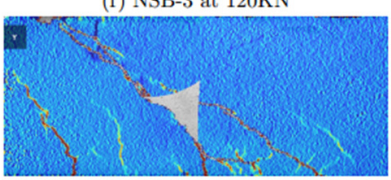

(h) NSB-3 at $140 \mathrm{KN}$

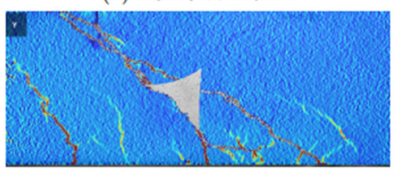

(j) NSB-3 at $150 \mathrm{KN}$
Fig. 11. Crack evolution observed from DIC and corresponding loading force of beam specimens WRB-3 and NSB-3.

\section{2) Crack Development}

Figures 11 and 12 present the crack evolution for beam specimens at different loads during the test. It can be seen from these figures that both flexural and diagonal cracks started earlier in the NSB specimens regardless of the fact that both beams reached the same value of ultimate load in loaddisplacement curves. It is also worth noting that the first diagonal crack appeared at the load of $85 \mathrm{kN}$ for the specimen NSB-3 and at $138 \mathrm{kN}$ for the WRB-3. There was an increase of $48 \%$ of the diagonal cracking load when the normal stirrups were replaced with continuous spiral-type wire rope shear reinforcement. The same observation about crack evolution in the beam specimens WRB-2 and NSB-2 is shown in Figure 14. It can be seen that at a load of $109 \mathrm{kN}$, a diagonal crack had already formed in the beam with normal stirrups. At a load of $130 \mathrm{kN}$, diagonal cracks only started to form in the beam specimen WRB-2 and a complete diagonal crack only appeared at a load of $157 \mathrm{kN}$, which corresponds to an increase of about $50 \%$. Due to the observed behavior between the specimens WRB-3 and NSB-3 shown in Figures 5 and 11, it seems important to study the crack evolution of these specimens in order to better understand the change of beam stiffness. A possible explanation to this difference in behavior could be, as reported in [1,7], that spiral configuration enhanced concrete compressive strength due to its confinement effect, which leads to an increase of shear load for which the development of the first inclined crack in the specimen WRB is observed.

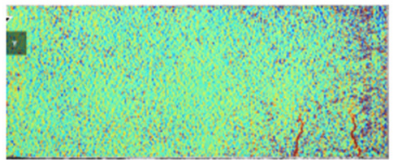

(a) WRB-2 at $50 \mathrm{KN}$

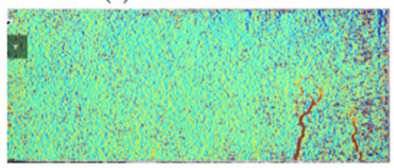

(c) WRB-2 at $70 \mathrm{KN}$

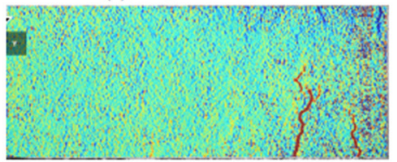

(e) WRB-2 at $90 \mathrm{KN}$

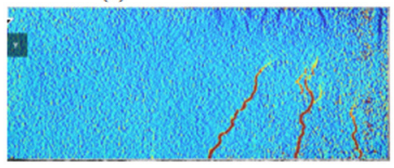

(g) WRB-2 at $110 \mathrm{KN}$

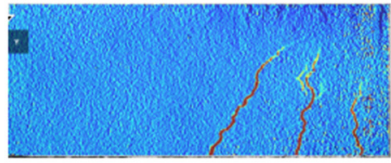

(i) WRB-2 at $130 \mathrm{KN}$

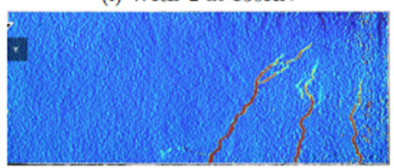

(k) WRB-2 at $150 \mathrm{KN}$

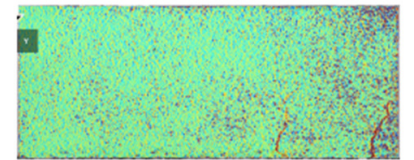

(b) NSB-2 at $50 \mathrm{KN}$

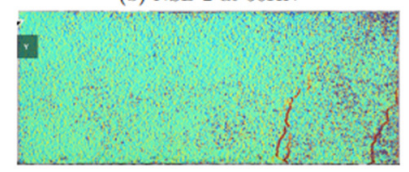

(d) NSB-2 at $70 \mathrm{KN}$

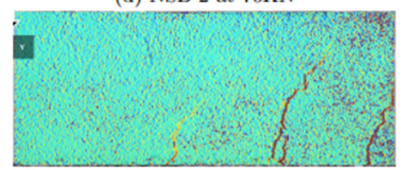

(f) NSB-2 at $90 \mathrm{KN}$

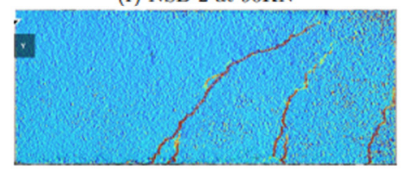

(h) NSB-2 at $110 \mathrm{KN}$

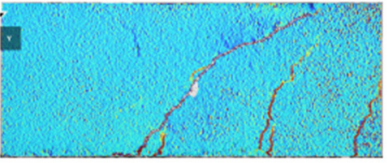

(j) NSB-2 at $130 \mathrm{KN}$

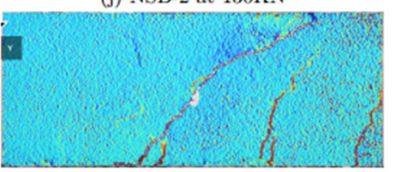

(1) NSB-2 at $150 \mathrm{KN}$
Fig. 12. Crack evolution observed from DIC and corresponding loading force of beam specimens NSB-2 and WRB-2.

According to [21], the appearance of the diagonal cracking in beams with wire ropes led to a strong diminution of the stiffness of the beams. Indeed after the appearance of the first diagonal crack in the continuous spiral-type wire rope shear reinforced beams (see Figure 5), it was observed that the beam stiffness was strongly degraded until it reached ultimate load compared to the beams with conventional stirrups. This observation leads to the postulation that stiffness degradation in the WRB specimens after the initiation of the first diagonal crack could be attributed to the weaker bond between the wire rope reinforcement and concrete. It is well known that the role of web reinforcement is to prevent further cracking through the stress transfer between the concrete and the web reinforcement [22]. Since the wire rope has a weaker bond compared to conventional stirrups due to its geometrical configuration, its effectiveness in stress transfer is weaker than that of conventional stirrups. From Figure 6, it is possible that the sudden drop of shear resistance in the beam specimen WRB-2 
could be explained by the loss of bond between concrete and the wire ropes. Figure 14 shows cracks at point $C$ and point $D$ of Figure 6. Figure 14(b) indicates the formation of extra cracks on the beam specimen which could be attributed to loss of concrete resistance. Indeed greater confinement of the concrete increased not only the resistance but also the fragility of the concrete, which could explain the sudden fall in beam resistance.

\section{Crack Widths}

Crack widths were obtained by post processing the displacement fields obtained from DIC results. In order to focus on larger crack widths, a thorough analysis for different locations within the crack direction was performed. Crack width is the normal of the vector $\mathrm{AB}$ as shown in Figure 13. The obtained crack width values were then plotted versus the applied force as shown on Figure 15. These figures also reveal the load difference at the formation of the first diagonal cracks in the beam specimens. Results presented in these figures are in good agreement with the corresponding images shown in Figures 11 and 12 and also the load-deflection curves shown in Figures 6 and 7. From Figure 15(a), it can be seen that crack width varied linearly with applied load until it reached the crack opening value of $0.1 \mathrm{~mm}$. After this, the WRB specimen increased its crack width significantly under small increase of load compared to NSB specimen. Figure 15(b) shows that beam specimen NSB-2 was more resistant to crack opening compared to the WRB specimen until the formation of the first diagonal crack.

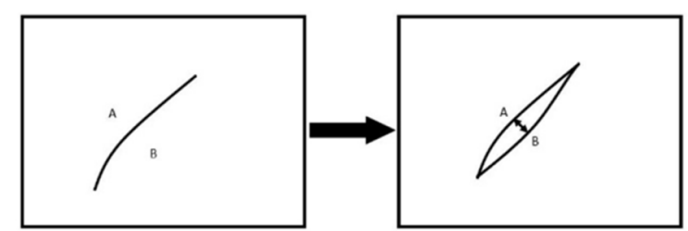

Fig. 13. Determination of the crack width.

Crack width is an important design aspect for the serviceability as well as the durability of reinforced concrete construction $[23,24]$. It was therefore important to record the load at which the serviceability limit of crack width was reached for the two types of beam specimens since this is structurally very significant. From Figure 15(a), we observe that the $0.3 \mathrm{~mm}$ serviceability crack width limit was reached at $87 \mathrm{kN}$ for the NSB and at $140 \mathrm{kN}$ for the WRB specimen. From Figure 15(b) the NSB specimens reached a crack opening of $0.3 \mathrm{~mm}$ at $105 \mathrm{kN}$ while the wire rope specimens reached it at $157 \mathrm{kN}$. From these figures it can be seen that WRB specimens reached the serviceability crack limit for higher loads than specimens with normal stirrups.

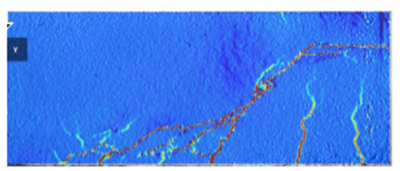

(a) WRB-2 at point C

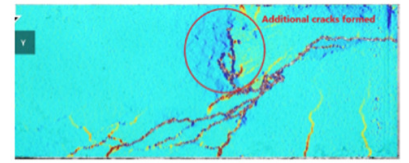

(b) WRB-2 at point D
Fig. 14. Strain fields measured from DIC for WRB-2 specimen at failure (points $\mathrm{C}$ and D of Figure 6).
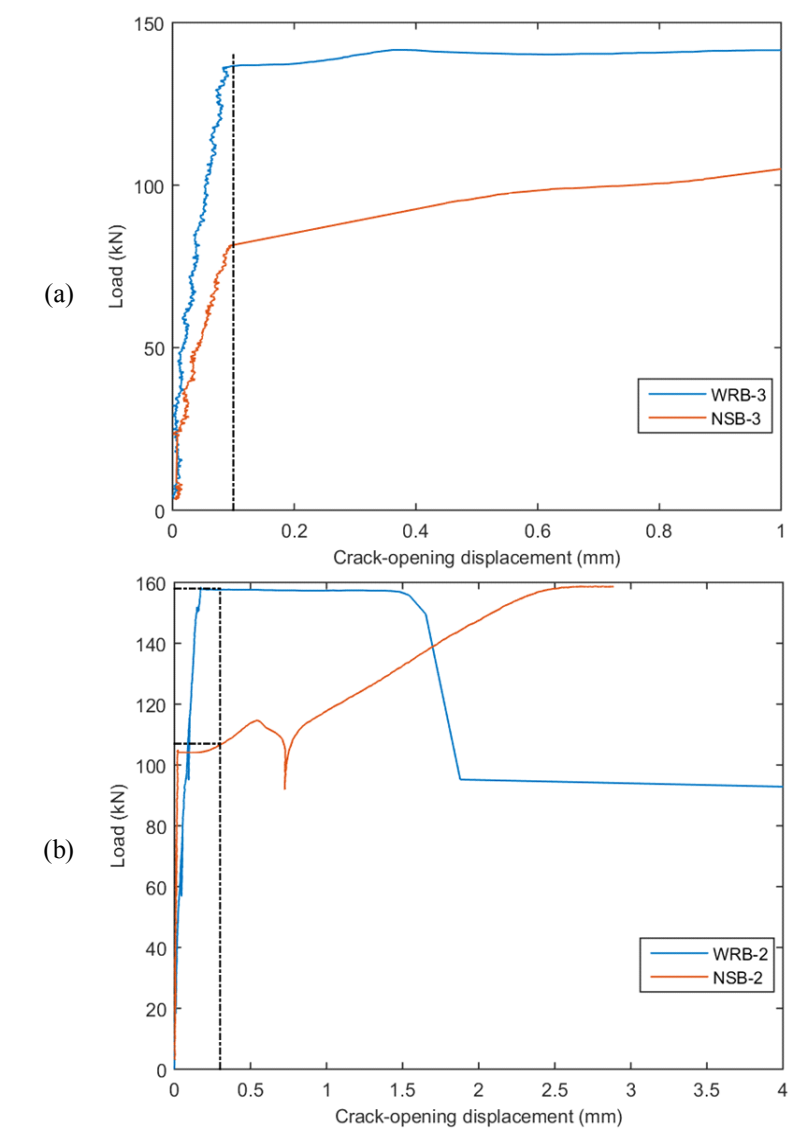

Fig. 15. Load-crack opening curves between point A and B of Figure 13: (a) WRB-3 and NSB-3, (b) WRB-2 and NSB-2.

\section{CONCLUSION}

Based on the results of our study and in order to determine shear response and the possibility of the practical application of wire ropes as internal shear reinforcement, the following conclusions were drawn:

- The continuous spiral-type wire rope beam specimens reached serviceability crack width limit at higher loading levels compared to the beams with normal stirrups.

- The beams with spiral-type wire ropes developed first diagonal cracks at higher loading than beams with closed stirrups. This shows that the cracking control capacity of the beams increased with the introduction of continuous spiral-type wire rope as internal shear reinforcements.

- The increasing rate of crack width in applied load was smaller in beams with spiral-type wire rope than in beams with normal stirrups.

- Bonding between spiral-type wire ropes and concrete appeared to be an important parameter that could significantly affect the ductility of beams with spiral-type wire ropes as shear reinforcement.

- Digital image correlation technique was found to be very effective in monitoring crack formation and propagation in concrete beams. 


\section{REFERENCES}

[1] K.-H. Yang, G.-H. Kim, and H.-S. Yang, "Shear behavior of continuous reinforced concrete T-beams using wire rope as internal shear reinforcement," Construction and Building Materials, vol. 25, no. 2, pp. 911-918, Feb. 2011, doi: 10.1016/j.conbuildmat.2010.06.093.

[2] L. Daudeville and Y. Malécot, "Concrete structures under impact," European Journal of Environmental and Civil Engineering, vol. 15, no. sup1, pp. 101-140, Jan. 2011, doi: 10.1080/19648189.2011.9695306.

[3] T. H. K. Kang et al., "Relief of Reinforcing Congestion in Beams and Bent Caps of Concrete Bridges," Oklahoma Transportation Center, Oklahoma, OK, USA, OTCREOS9.1-27-F, Jun. 2012. Accessed: Jun. 09, 2020. [Online]. Available: https://trid.trb.org/view/1262831.

[4] M. S. Sumpter, S. H. Rizkalla, and P. Zia, "Behavior of HighPerformance Steel as Shear Reinforcement for Concrete Beams," Structural Journal, vol. 106, no. 2, pp. 171-177, Mar. 2009, doi: $10.14359 / 56355$

[5] R. Narayanan and I. Y. S. Darwish, "Use of Steel Fibers as Shear Reinforcement," Structural Journal, vol. 84, no. 3, pp. 216-227, May 1987, doi: 10.14359/2654.

[6] Y.-K. Kwak, M. O. Eberhard, W.-S. Kim, and J. Kim, "Shear Strength of Steel Fiber-Reinforced Concrete Beams without Stirrups," Structural Journal, vol. 99, no. 4, pp. 530-538, Jul. 2002, doi: 10.14359/12122.

[7] Y.-K. Kwak, M. O. Eberhard, W.-S. Kim, and J. Kim, "Shear Strength of Steel Fiber-Reinforced Concrete Beams without Stirrups," Structural Journal, vol. 99, no. 4, pp. 530-538, Jul. 2002, doi: 10.14359/12122.

[8] B. Mas, A. Cladera, and C. Ribas, "Experimental study on concrete beams reinforced with pseudoelastic Ni-Ti continuous rectangular spiral reinforcement failing in shear," Engineering Structures, vol. 127, pp. 759-768, Nov. 2016, doi: 10.1016/j.engstruct.2016.09.022.

[9] C. Karayannis and G. Sirkelis, "Response of columns and joints with spiral shear reinforcement," WIT Transactions on Modelling and Simulation, vol. 41, 2005, doi: 10.2495/CMEM050441.

[10] S. A. Sheikh and M. T. Toklucu, "Reinforced Concrete Columns Confined by Circular Spirals and Hoops," Structural Journal, vol. 90, no. 5, pp. 542-553, Sep. 1993, doi: 10.14359/3949.

[11] D. J. Kakaletsis, C. G. Karayannis, and G. K. Panagopoulos, "Effectiveness of Rectangular Spiral Shear Reinforcement on Infilled R/C Frames Under Cyclic Loading," Journal of Earthquake Engineering, vol. 15, no. 8, pp. 1178-1193, Dec. 2011, doi: $10.1080 / 13632469.2011 .560361$.

[12] A. M. Budek, M. J. N. Priestley, and C. O. Lee, "Seismic Design of Columns with High-Strength Wire and Strand as Spiral Reinforcement," ACI Structural Journal, vol. 99, no. 5, pp. 660-670, Sep. 2002.

[13] D. Corr, M. Accardi, L. Graham-Brady, and S. Shah, "Digital image correlation analysis of interfacial debonding properties and fracture behavior in concrete," Engineering Fracture Mechanics, vol. 74, no. 1, pp. 109-121, Jan. 2007, doi: 10.1016/j.engfracmech.2006.01.035.

[14] L. Nunes, D. A. Castello, P. A. M. dos Santos, and C. F. T. Matt, "Identification of material properties using full-field and non contact measurements," Journal of the Brazilian Society of Mechanical Sciences and Engineering, vol. 31, no. 3, pp. 167-172, Jul. 2009, doi: 10.1590/S1678-58782009000300001

[15] B. Pan, K. Qian, H. Xie, and A. Asundi, "Two-dimensional digital image correlation for in-plane displacement and strain measurement: A review," Measurement Science and Technology, vol. 20, no. 6, Apr. 2009, Art no. 062001

[16] Y. Sieffert, F. Vieux-Champagne, S. Grange, P. Garnier, J. C. Duccini, and L. Daudeville, "Full-field measurement with a digital image correlation analysis of a shake table test on a timber-framed structure filled with stones and earth," Engineering Structures, vol. 123, pp. 451472, Sep. 2016, doi: 10.1016/j.engstruct.2016.06.009.

[17] T. M. Fayyad and J. M. Lees, "Application of Digital Image Correlation to Reinforced Concrete Fracture," Procedia Materials Science, vol. 3, pp. 1585-1590, Jan. 2014, doi: 10.1016/j.mspro.2014.06.256.

[18] M. Hamrat, B. Boulekbache, M. Chemrouk, and S. Amziane, "Flexural cracking behavior of normal strength, high strength and high strength fiber concrete beams, using Digital Image Correlation technique,"
Construction and Building Materials, vol. 106, pp. 678-692, Mar. 2016, doi: 10.1016/j.conbuildmat.2015.12.166.

[19] T. M. Fayyad and J. M. Lees, "Experimental investigation of crack propagation and crack branching in lightly reinforced concrete beams using digital image correlation," Engineering Fracture Mechanics, vol. 182, pp. 487-505, Sep. 2017, doi: 10.1016/j.engfracmech.2017.04.051.

[20] J. Blaber, B. Adair, and A. Antoniou, "Ncorr: Open-Source 2D Digital Image Correlation Matlab Software," Experimental Mechanics, vol. 55, no. 6, pp. 1105-1122, Jul. 2015, doi: 10.1007/s1 1340-015-0009-1.

[21] J. Niwa, K. Yamada, K. Yokozawa, and H. Okamura, "Revaluation of the equation for shear strength of reinforced concrete beams without web reinforcement," (in Japanese), Doboku Gakkai Ronbunshu, vol. 1986, no. 372, pp. 167-176, 1986, doi: 10.2208/jscej.1986.372_167.

[22] J. G. MacGregor, Reinforced concrete: Mechanics and design, 3rd ed. Upper Saddle River, NJ, USA: Prentice Hall, 1997.

[23] R. Park and T. Paulay, Reinforced Concrete Structures, New York, NY, USA: Wiley, 1974.

[24] Eurocode 2: Design of concrete structures-Part 1-1: General rules and rules for buildings, ICS 91.010.30; 91.080.40, CEN, Brussels, Belgium, 2004. 